\title{
(RE)PENSANDO AS PRÁTICAS DE ESCRITA NA DISCIPLINA DE ESTÁGIO SUPERVISIONADO EM QUIIMICA: COM A PALAVRA, OS ESTAGIÁRIOS
}

\author{
Wallace Alves Cabra* ${ }^{*}$ \\ Cristhiane Carneiro Cunha Flôr **
}

RESUMO: Apresentamos nesta pesquisa uma proposta que foi desenvolvida com os estudantes da disciplina de Estágio Supervisionado em Química da UFJF no ano de 2013, buscando (re) pensar as práticas de escrita para além dos relatórios técnicos que comumente são desenvolvidos neste momento da formação inicial. Nesse sentido, a partir das observações escolares e dos estudos nas dependências da UFJF, os estudantes produziram quatro relatos, que foram elaborados em um processo dialógico de escrita e (re) escrita. Em uma roda de conversas, os estudantes falaram sobre esse movimento na disciplina de estágio. De modo geral, os estagiários apontaram como essencial esse processo de (re)escrever os relatos durante os dois semestres letivos, permitindo uma reflexão sobre a prática e um aprofundamento quanto às questões postas.

Palavras-chave: Escrita. Estágio Supervisionado. Formação de professores.

\section{(RE)PENSANDO LAS PRACTICAS DE ESCRITURA EN LA CLASE DE PASANTIA SUPERVISADA EN LA QUIMICA: CON LA PALABRA, LOS PASANTES}

RESUMEN: Presentamos en esta investigación una propuesta desarrollada con los estudiantes de la clase Pasantía Supervisada en la Química de UFJF en el año 2013, buscando (re)pensar las prácticas de escritura para además de los informes técnicos que son comúnmente desarrollados en este momento de formación inicial. En este sentido, a partir de las observaciones escolares y de los estudios en las dependencias de UFJF, los estudiantes produjeron cuatro relatos, que fueron elaborados en un proceso dialógico de escritura y (re)escritura. En un círculo de conversación, los estudiantes hablaron sobre ese movimiento en la clase de pasantía. En general, los pasantes apuntaron como esencial ese proceso de (re)escribir los relatos durante los dos semestres, permitiendo una reflexión sobre la práctica y una profundización acerca de las cuestiones puestas.

Palabras clave: Escritura. Pasantía supervisada. Formación de profesores. 


\section{(RE)THINKING WRITING PRACTICES ON SUPERVISED INTERNSHIP IN CHEMISTRY: INTERNS' POINT OF VIEW}

ABSTRACT: We present in this research a proposal that was developed with the Supervised Internship in Chemistry class' students at UFJF, in 2013. We sought to (re)think writing practices beyond the technical reports that are commonly developed during initial formation. In this sense, from school observations and studies on UFJF's premises, the students produced four reports, which were prepared in a dialogic process of writing and (re)writing. In conversation meetings, the students talked about writing processes at the internship discipline. In general, the trainees pointed out how essential this process of (re) writing reports during the two semesters, allowing a reflection on the practice and a deepening of the questions proposed.

Keywords: Writing. Internship. Teacher training. 


\section{ESCREVER NA DISCIPLINA DE ESTÁGIO NA FORMAC̣̃̃O DE PROFESSORES DE QUIIMICA: ALGUMAS REFLEXÕES}

Ao pensarmos a formação inicial de professores em cursos de Licenciatura, diferentes olhares podem ser lançados, dependendo do foco que se dá à questão. Um tema que tem despertado o interesse de pesquisadores atualmente diz respeito às disciplinas de Estágio Supervisionado, e a intensificação das discussões em torno dessa disciplina pode ser vista como desdobramento das proposições apresentadas nas Diretrizes Curriculares Nacionais para a formação de professores. No presente trabalho, apresentaremos algumas atividades de leitura e escrita desenvolvidas no âmbito da disciplina de Estágio Supervisionado em Química, por meio das quais buscamos, a partir da formação inicial, fomentar o surgimento de professores leitores e escritores da química e do mundo.

Há certo consenso na comunidade acadêmica de que o Estágio Supervisionado, apesar de todas as limitações encontradas - número elevado de alunos nas turmas, atividades distantes da realidade concreta das escolas, dicotomia entre teoria e prática, agregado de atividades técnicas e burocráticas e outros - tem uma função primordial na formação inicial nos cursos de Licenciatura, seja na fase de observação, de participação, ou na regência. Acredita-se que o estagiário tem a possibilidade de se colocar em posição de refletir, construindo, desconstruindo e reconstruindo expectativas sobre a profissão docente a partir do contato direto com realidades da escola, como apontam Baccon e Arruda (2010), Kasseboehmer e Ferreira (2008), Silva e Schnetzler (2008), Pimenta (2012) e outros. Nesse sentido,

Como componente curricular, o Estágio pode não ser uma completa preparação para o magistério, mas é possível nesse espaço, professores, alunos e comunidade escolar e universidade trabalharem questões básicas de alicerce, a saber: o sentido da profissão, o que é ser professor na sociedade em que vivemos, como ser professor, a escola concreta, a realidade dos alunos nas escolas de ensino fundamental e médio, a realidade dos professores nessas escolas, entre outras. (PIMENTA; LIMA, 2012, p. 100)

Pensar o Estágio Supervisionado é considerá-lo como um importante espaço no que diz respeito à formação de professores. O Estágio curricular, "cuja finalidade é integrar o processo de formação do aluno, de modo a considerar o campo de atuação como objeto de análise, de investigação e de interpretação crítica, a partir dos nexos com as disciplinas do curso" (PIMENTA; LIMA, 2012, p. 24), deve ser considerado uma atividade que permite ao estudante um contato com diferentes realidades educacionais, compondo com as teorias existentes possibilidades de reflexão e ação no campo profissional.

A intensificação das discussões em torno dessa disciplina é decorrente das Diretrizes Curriculares Nacionais para a formação de professores, a partir das quais busca-se abandonar o modelo da racionalidade técnica, que "[...] se caracteriza, dentre outros aspectos, pela valorização da instrumentalidade técnica para a resolução dos problemas educacionais" (GONÇALVES; FERNANDES, 2010, p. 127). Esse modelo, ainda hoje, permanece presente na formação de professores. O enfoque na técnica e nas teorias como única forma verdadeira de 
conhecimento admissível e como conhecimento objetivo, que deve ser "aplicado" na escola - ambiente desprovido de conhecimento pedagógico -, ainda perpassa muitas práticas e discursos na formação de professores.

Entre tantas consequências dessa visão na formação de professores, em geral e, em particular, de Química, podemos pensar nos impactos nos processos de leitura e escrita os quais os professores em formação vivenciam. Concordamos com Colello (2012, p. 50) quando diz que saber ler e escrever vai além da capacidade de copiar e decodificar textos, sendo um "instrumento de comunicação e expressão, meio de ampliar contatos, de se fazer presente no mundo ou compreendê-lo, enfim, a possibilidade de estabelecer outros canais de interlocução, inserindo-se ativa e criticamente em práticas da sociedade letrada".

A prática da escrita já se constitui, ainda que incipiente, como objeto de estudo na área de Ciências. Sabemos que, no ensino escolar, as atividades de escrita, algumas vezes, envolvem apenas o exercício mecânico de ideias, sem que ocorra propriamente elaboração e reflexão pelos estudantes, como destacam Almeida, Cassiani e Oliveira (2008, p. 37). Se analisarmos essa situação no Ensino Superior, em específico na formação inicial de professores de química, esse caso se repete. Queiroz (2001) destaca que os cursos de Química universitária (e de Licenciatura em Química) têm sido potencialmente quantitativos, com ênfase em habilidades de cálculo e resolução de problemas, em prejuízo do desenvolvimento de habilidades qualitativas, como a capacidade de argumentação oral e escrita.

Levando em conta a necessidade de refletir sobre a escrita, sem apenas pensá-la como atividade que pode contribuir para a formação de conceitos científicos pelos estudantes, Cassiani e Almeida (2005) propõem dimensionar a escrita como possibilidade de expressão do pensamento dos estudantes nas aulas de Ciências do $9^{\circ}$ ano, evidenciando diferentes possibilidades de estratégias de escrita como mediadoras de manifestações dos estudantes, como a produção de histórias de ficção científica, diário de bordo e carta, as autoras concluem que é notória a potencialidade dessas estratégias para o desenvolvimento da escrita e discussões de questões ligadas às Ciências. Além disso, é perceptível o empenho, o envolvimento e a empolgação frente a essa atividade.

Já Cassiani e Nascimento (2006) resgatam as histórias de leituras dos licenciandos em Ciências Biológicas através de relatos escritos, destacando que muitos deles disseram não ter escrito nada de cunho pessoal durante os quatro anos de graduação. Como apontado por Queiroz (2001), tendo em vista o caráter prioritariamente quantitativo das atividades e das habilidades trabalhadas, nos cursos de Química, essa realidade não é muito diferente. Francisco Júnior (2011) destaca que é comum a reclamação de estudantes de graduação em Química, ou outras áreas de conhecimento, acerca das dificuldades em registrar por escrito o que pensam. Segundo o autor, o âmago desse problema, nos cursos de Formação de Professores, é a carência de uma escrita discursiva, compreensiva e interpretativa, ou seja, aquela que não procura apenas perceber logicamente o que se escreve, mas que busca explorar os múltiplos significados das ideias.

Lançando um olhar para as práticas de escrita na disciplina de Estágio, percebemos que ainda é recorrente em cursos de formação de professores a produção de relatórios como formato de trabalho para justificar a atribuição de 
notas ou conceito por docentes responsáveis pela disciplina e, ainda, sem a devida reflexão e discussão sobre o material produzido. Silva (2012, p. 12), investigando as potencialidades dos relatórios de estágio produzidos em quatro licenciaturas da Universidade Federal do Tocantins, aponta que "os usos dos relatórios de estágio parecem não se configurar em práticas de escrita acadêmica significativas para a formação de professores autônomos".

Acreditamos em uma escrita que se afasta da produção de relatórios técnicos, concordando com Colello (2012, p. 11) que "não é possível semear a competência na escrita com base apenas em relatórios técnicos, ou em fatos objetivos". Aproximamos da perspectiva de Cassiani e Almeida (2005), uma vez que propõe uma nova forma para se olhar para os relatórios de Estágio e de se ler o ambiente escolar.

Pensando nisso, ancoramos nossas atividades de reflexão a respeito da escrita na produção de relatos, que se configuram como um documento pessoal, na qual são abordados assuntos relevantes sobre o trabalho ou a observação que está sendo feita. Gonçalves et al. (2008) afirma que os relatos nos cursos de Licenciatura proporcionam a reflexão pela escrita com intuito de favorecer aprendizagens sobre ser professor. Somado a isso, Colello (2012, p. 27) destaca que o estudante que é produtor de textos tem o desafio da produção da escrita e, ao mesmo tempo, a satisfação de poder dar vida aos seus pensamentos, a suas ideias e fantasias.

Para compreender os processos constitutivos da linguagem, buscamos aporte teórico e metodológico na Análise do Discurso de Linha Francesa, na obra de Michel Pêcheux e seu desdobramento no Brasil através dos trabalhos de Eni Orlandi (2012). Entendemos que todo leitor tem sua história de leituras, que vai guiá-lo na produção de sentidos para determinado contexto e na forma como escreve e relata suas leituras de mundo.

Partindo dessas considerações, propomos (re)pensar as práticas de escrita de relatórios técnicos, que comumente são realizadas na disciplina de Estágio, e apresentar a atividade de escrita e elaboração de um livro de relatos pelos estudantes da Licenciatura em Química da UFJF.

\section{A ESCRITA DE RELATOS COMO PONTE PARA O DIÁLOGO}

Foram desenvolvidas atividades de escrita de relatos durante os dois semestres letivos do ano de 2013 com estudantes das disciplinas de Estágio Supervisionado em Química I e Estágio Supervisionado em Química II na Faculdade de Educação da UFJF. Essas são disciplinas obrigatórias para o curso de Licenciatura em Química, com carga horária de 200 horas cada, que se alternam entre 140 horas de atividades a serem desenvolvidas no ambiente escolar e 60 horas presenciais na UFJF, com encontros semanais para estudos e reflexões. No primeiro semestre letivo, tivemos a disciplina de Estágio Supervisionado em Química I com cinco estudantes matriculados; já no segundo semestre, a disciplina de Estágio Supervisionado em Química II teve apenas quatro estudantes matriculados. Para esse trabalho, consideraremos os relatos produzidos pelos quatro estudantes que 
concluíram as duas disciplinas. As disciplinas foram acompanhadas, ainda, por um pesquisador, estudante de mestrado (do qual este estudo é um recorte), e por uma monitora, os quais frequentaram todos os encontros presenciais, recolheram os relatos e participaram ativamente do diálogo com os estudantes.

Partindo das observações escolares e das discussões ocorridas nos encontros presenciais semanais na UFJF, foram produzidos quatro relatos no decorrer dos dois semestres. A distribuição dos exercícios de escrita durante as disciplinas foi a seguinte:

QUADRO 1 - Atividades e temas trabalhados na escrita dos relatos

\begin{tabular}{|c|c|c|c|}
\hline Disciplina & $\begin{array}{c}\text { Atividades } \\
\text { desenvolvidas }\end{array}$ & $\begin{array}{c}\text { Temas dos relatos } \\
\text { produzidos }\end{array}$ & Formato dos relatos \\
\hline $\begin{array}{c}\text { Estágio } \\
\text { Supervisionado } \\
\text { em Química I }\end{array}$ & $\begin{array}{c}\text { Exercício de } \\
\text { Estranhamento }\end{array}$ & $\begin{array}{l}\text { A desnaturalização do } \\
\text { ambiente escolar a } \\
\text { partir do exercício de } \\
\text { estranhamento }\end{array}$ & $\begin{array}{c}3 \\
\text { relatos escritos e } 1 \\
\text { PowerPoint }\end{array}$ \\
\hline \multirow{4}{*}{$\begin{array}{c}\text { Estágio } \\
\text { Supervisionado } \\
\text { em Química II }\end{array}$} & $\begin{array}{l}\text { Desdobramento } \\
\text { do Exercício de } \\
\text { Estranhamento }\end{array}$ & $\begin{array}{c}\text { O que fica de comum } \\
\text { quando estranhamos a } \\
\text { escola? } \\
\text { O tempo escolar } \\
\text { O uniforme escolar } \\
\text { O espaço físico escolar }\end{array}$ & $\begin{array}{l}4 \\
\text { relatos escritos }\end{array}$ \\
\hline & $\begin{array}{c}\text { A relação } \\
\text { professor-aluno }\end{array}$ & $\begin{array}{c}\text { A relação professor-aluno } \\
\text { na escola }\end{array}$ & $\begin{array}{c}4 \\
\text { relatos escritos }\end{array}$ \\
\hline & Regência de Classe & A experiência da docência & $\begin{array}{c}4 \\
\text { relatos escritos }\end{array}$ \\
\hline & $\begin{array}{c}\text { Construção do livro } \\
\text { de relatos }\end{array}$ & $\begin{array}{c}\text { Todos os temas descritos } \\
\text { anteriormente }\end{array}$ & $\begin{array}{l}\text { Cada capítulo foi } \\
\text { formado pelos } \\
\text { relatos produzidos } \\
\text { por cada estudante }\end{array}$ \\
\hline
\end{tabular}

Fonte: Elaboração pelos autores deste artigo.

Os relatos apontados no quadro acima foram produzidos num movimento dialógico entre estudantes, pesquisador, monitor e professora da disciplina. Nessa dinâmica, os relatos eram produzidos em versão preliminar e entregues em data marcada. Na sequência, eram lidos pela professora, pelo pesquisador e pela monitora, que faziam comentários, observações e correções. Os relatos eram, então, devolvidos aos estudantes, para que realizassem as mudanças necessárias e os reapresentassem. A dinâmica era, então, repetida a fim de chegarmos a uma versão final do relato. Uma exceção a esse movimento foi o primeiro relato, o do Exercício de Estranhamento, que, por ter um caráter exclusivamente criativo, sem necessidade de aportes teóricos nem rigor de estilo na apresentação das observações, não sofreu alterações, a não ser de correção gramatical e ortográfica. 
Para o Exercício de Estranhamento, o gênero textual adotado pelo estudante/ escritor foi deixado livre, podendo assumir diferentes formatos: vídeos, PowerPoints, cartazes, desenhos, textos escritos e outros.

A seguir, serão apresentados os principais aspectos das atividades que subsidiaram a escrita dos relatos.

Exercício de Estranhamento - Como indicado, o primeiro relato de observação escolar se deu a partir da atividade denominada exercício de estranhamento, discutida em trabalho anterior por Flôr e Cabral (2012). Nessa atividade, os estudantes foram chamados a desnaturalizar o ambiente escolar, assim como o autor Horace Miner (1976) faz em seu texto Os ritos corporais entre os Nacirema. A proposta é que os estudantes ampliem seu olhar para a escola estranhando-a e fazendo um movimento discursivo de deslocamento, da formação discursiva pedagógica para a formação discursiva antropológica. Assim, os estudantes precisam desnaturalizar seu olhar para a escola e registrar suas impressões na forma de um relato que, no semestre em questão, foi apresentado por três estudantes na forma de escrita em prosa, e por um estudante, no formato PowerPoint.

Desdobramentos do Exercício de Estranhamento - Partindo da leitura em conjunto desses relatos nas dependências da UFJF, estabelecemos uma roda de discussão, buscando, juntos, entre os sentidos atribuídos pelos estudantes ao ambiente escolar, aqueles que mais se destacaram. Nessa turma, foram ressaltados os seguintes temas:

1. Tempo escolar: todos os relatos são marcados por reflexões a respeito do tempo e da forma como este se configura e é gerenciado na escola. Podemos perceber estas marcas na escrita dos estudantes ${ }^{1}$ :

Alexandre: Passou aproximadamente 2 horas e aquela sirene voltou a tocar, as pessoas em minha volta comemoravam, se levantavam e saiam da sala.

Adrian: De repente o barulho surge novamente como quem autorizasse a saida daquele ser que traçava os sinais [...].

2. Espaço físico da escola: As características do espaço escolar também marcaram os exercícios de estranhamento dos estudantes, como aparece nos trechos:

Fernanda: Mas era amplo e bem iluminado por materiais que curiosamente iluminavam sem ajuda de chamas [...].

Nena: Seus filhos, curumins e maiores, todos os dias frequentavam um templo onde recebiam ensinamentos.

3. Uniforme escolar: O uniforme escolar também é algo marcante em todos os relatos e se apresenta aos estudantes como uma marca do estar na escola:

Adrian: [...] e os que têm o corpo coberto pelo tecido branco, saem às pressas!

Nena: Eles cobriam o corpo com vestes iguais e sempre na mesma hora do dia entravam no templo e lá permaneciam até a hora do sol sobre nossas cabeças. 
Partindo desses três temas que surgiram após a leitura e a discussão dos exercícios de estranhamento, os estudantes puderam optar por se aprofundar em um deles e iniciaram novas leituras, buscando o diálogo entre referenciais teóricos e a realidade vivenciada na escola, o que, para Orlandi (2012), marca a noção de intertextualidade, que remete ao fato de que um texto nasce em outros textos, assim como também aponta para outros tantos. Como produto dessa discussão, das novas leituras e observações na escola, um novo relato foi produzido.

A relação professor-aluno - As características e as nuances da relação entre professores e estudantes foram o tema trazido para discussão pela professora da disciplina, o pesquisador e a monitora. Optamos por essa temática por estar muito presente nos relatos orais dos licenciandos a respeito de suas observações na escola e, também, por considerarmos tratar-se de um desafio para professores em início de carreira. Para trabalhá-la, assistimos ao filme francês $A$ voz do Coração, que retrata os desafios e as estratégias de um professor de música em um orfanato na França em 1949. O filme não apresenta uma perspectiva pedagógica ou um método, mas, sim, trata da ética, da sensibilidade e do valor do professor em suas relações com os estudantes. Após assistir ao filme, houve uma conversa sobre o tema e como os licenciandos o percebem em sua vivência na escola. $O$ terceiro relato foi, então, proposto e escrito na mesma dinâmica que o anterior.

Regência de Classe - Ao final de cada uma das duas disciplinas de estágio, os estudantes realizaram a intervenção nas escolas, lecionando para as turmas escolhidas. É importante salientar que este trabalho apresenta apenas as atividades desenvolvidas no sentido de subsidiar a escrita dos relatos. Nas disciplinas, os licenciandos ainda elaboraram planos de aula, que foram apreciados, discutidos e postos em prática nas escolas onde realizavam os estágios. Partindo da construção do plano de aula, da discussão e da intervenção nas escolas, os estagiários produziram o último relato sobre a experiência da docência, apontando os desafios, as limitações, as expectativas nas aulas ministradas e outras discussões pertinentes.

Livro de Relatos - Ao final da disciplina de Estágio Supervisionado em Química II, todos os relatos produzidos pelos quatro estudantes foram compilados em um livro de Estágio, sendo cada estudante responsável pela escrita de um capítulo. Para isso, os estudantes criaram uma capa e indicaram um título para esse livro, além de buscar articulações entre os relatos escritos de forma a dar coesão e coerência interna ao capítulo. O livro foi salvo em uma mídia digital (CD) e entregue aos membros da escola - professor, orientador e direção - como retorno das atividades e as reflexões propiciadas por aquele ambiente.

Construído o livro de relatos e finalizadas as duas disciplinas de estágio, os estudantes participaram de uma roda de conversa com o intuito de compreender as influências das atividades desenvolvidas e os caminhos trilhados em seus hábitos de escrita. A roda de conversa foi composta pelos quatro estudantes que concluíram a disciplina de Estágio Supervisionado em Química II e o pesquisador. Finalizada a roda de conversas, as falas dos estudantes foram transcritas e utilizados nomes fictícios, indicados pelos próprios estagiários. $\mathrm{Na}$ sequência deste trabalho, daremos ênfase às discussões em torno da produção de relatórios técnicos versus produção de relatos, movimento de escrita e reescrita dos relatos e, por fim, às contribuições da 
produção do livro de relatos para a formação de professores de química, na perspectiva dos estudantes.

\title{
ESCREVER NA DISCIPLINA DE ESTÁGIO SUPERVISIONADO EM QUÍMICA: ALGUMAS CONSIDERAÇÕES
}

Considerando os movimentos de leitura e escrita que foram realizados na produção dos relatos até a construção do livro, perguntamos aos estudantes, na roda de conversas, sobre a preferência da escrita: na forma de relatórios ou no formato de relatos. O estagiário Adrian mencionou a produção de relatos como uma atividade prazerosa e a escrita de relatórios técnicos como "chato".

\footnotetext{
Adrian: Na forma de relatos é mais agradável de se fazer. Você não tem que se preocupar com [...] a formatação do texto. A introdução, aquele relatório, a introdução, metodologia, procedimento, resultado, aquilo é chato.
}

Essa percepção de escrita por prazer se aproxima da pesquisa de Cassiani e Almeida (2005), evidenciando que diferentes possibilidades de estratégias de escrita como mediadoras de manifestação dos estudantes apresentam potencialidades para o desenvolvimento da escrita, além de perceber maior empenho, envolvimento e empolgação frente a essas atividades.

Adrian, em outro instante da roda de conversas, reforça o caráter mecânico na produção de relatório técnico e apresenta indícios de que esse formato de escrita imposto na disciplina favorece a reflexão e a possibilidade de se perceber como autor e produtor de textos.

\begin{abstract}
Adrian: [...] Relatório é muito frio. Você bota uma introdução lá, que isso você pode tirar de qualquer livro ou até mesmo na internet. A metodologia é o passo a passo do que você está fažendo. Então, essa narração dá mais frieza. Tira um pouco do sentimentalismo do texto, entendeu? Já o relato não, você busca escrever com suas palavras partindo que está observando, e aí, como vocês pediram, nós vamos buscando textos para dialogar, né?
\end{abstract}

Como destaca Colello (2012, p. 27), o estudante que é produtor de textos tem o desafio da produção da escrita e, ao mesmo tempo, a satisfação de poder dar vida aos seus pensamentos e às suas ideias. Somado a isso, Geraldi (1996) ressalta que essa relação "autor-escrita" permite aventurar-se na língua, em projetos pessoais/coletivos de pesquisa, reflexão, aprendizagem e, certamente, reorganização do universo simbólico que permeia a atividade.

$\mathrm{Na}$ mesma direção de Adrian, a estudante Fernanda prefere a escrita de relatos, apontando esse formato como "mais rico e prazeroso". Além disso, a estagiária destaca: "Sem contar que ao escrever nesse formato, você aprende a fazer algo que é essencial mesmo pra um acadêmico, né?" (Fernanda).

Apesar de perceber a produção de relatos como prazerosa, a estagiária não desvincula esse formato da produção acadêmica, pensando os relatos como ferramentas para potencializar a escrita científica, como apresentam os trabalhos de Queiroz (2001). 
Os estagiários Nena e Alexandre apontaram a preferência da escrita no formato de relato, porém, Alexandre considerou difícil esse processo de "criação":

\begin{abstract}
Alexandre: Essa disciplina foi realmente muito importante pra gente. Inclusive porque esse processo de reescrever, acho que é bem complicado. Às vezes eu acho que, o pessoal pode não ter essa mesma impressão, mas eu tava olhando os textos que produzi: 'nossa, foi eu que escrevi isso?'. Acho que foi bem interessante esse processo de escrita e criação do relato. Foi dificil, mas acho que foi bem legal esse retorno assim.
\end{abstract}

É importante perceber, na fala de Alexandre, a dicotomia que se tem estabelecido entre os estudantes dessa disciplina; de um lado temos a produção de relatos como processo criativo, prazeroso e que possibilita a inserção da própria opinião, e do outro lado, a elaboração dos relatórios técnicos, sendo uma escrita mecânica, não prazerosa e que há pouca/nenhuma reflexão sobre aquilo que se produz. Somado a isso, Nena aponta a importância dos relatos como possibilidade de estabelecer relações intertextuais: “...vai dando ligação pra aquilo que você escreve, é bem interessante. É muito mais construtivo pro formando" (Nena).

Partindo dessas considerações, pode-se perceber a preferência dos estudantes pela produção de relatos nas disciplinas de Estágio. Nesse sentido, questionamos os estudantes sobre a experiência de escrever e reescrever os relatos a partir dos comentários de outros leitores. Como dito, os estudantes foram convidados a revisitar seus relatos e, ao longo desse processo, os trabalhos foram comentados com dicas e sugestões para reflexão e desenvolvimento. Essa leitura comentada foi realizada pelos pesquisadores e a monitora da disciplina. A respeito desse processo, todos os estudantes falaram da importância de reescrever a partir da leitura e dos comentários de outro leitor, como pode ser exemplificado na fala da Fernanda:

Fernanda: Eu vejo isso como essencial, porque é mais uma forma de desnaturalizar aquilo que você escreve. A pessoa que tá lendo, que não é você, você está lendo, relendo aquele texto, aquilo fica tão natural pra você, que você não consegue enxergar outras coisas, que outra pessoa, por exemplo, que passa por você, pela matéria, pela professora da disciplina, quando vai reler, ele já vem outras coisas que pode acrescentar, que pode estar melhorando no texto. Eu acho que é essencial e que tem que ter mesmo, esses comentários.

A fala da estagiária Fernanda apresenta marcas das discussões realizadas anteriormente sobre a atividade Exercício de Estranhamento, considerando importante a leitura e os comentários de outros leitores com intuito de desnaturalizar aspectos naturalizados em sua leitura. Essa relação estabelecida pela estagiária marca a noção de relação de sentidos discutida por Orlandi (2012, p. 39): "Segundo essa noção, não há discurso que não se relacione com outros. Em outras palavras, os sentidos resultam de relações: um discurso aponta para outros que o sustentam, assim como para dizeres futuros".

Esse trabalho de leitura e reescrita se aproxima de Orlandi (2012, p. 116), com o conceito de pluralidade de leituras: "não estou pensando apenas na leitura de vários textos, mas, sobretudo, na possibilidade de se ler um mesmo texto de várias maneiras. Este é um aspecto fundamental do processo de significação que a leitura estabelece". Além disso, quando a estudante aponta como essencial a 
leitura de outro leitor, evidencia a sua visão de não considerar a linguagem como transparente, uma vez que outros leitores realizarão diferentes leituras de acordo com seu histórico de leituras.

Já a estagiária Nena, ao falar sobre a importância desse processo, parece considerar a linguagem como transparente, remetendo ao fato de haver sentidos prontos e únicos por trás de um texto, esperando para ser decifrados. "[...] Tem que fazer dessa forma mesmo. Pra poder chegar num texto final, que eu já vou ter entendido, que todo mundo consegue interpretar da mesma forma, né?" (Nena).

Nena ainda destaca a necessidade de trabalhar com diferentes gêneros textuais na formação inicial:

Nena: É, eu acho que tem que ter essa avaliação, tem que ter uma ajuda, porque pra construir esses tipos de textos, como que a gente não tem uma disciplina pra orientar, alguém tem que orientar, né? Tem que fazer dessa forma mesmo.

Outra característica marcante na fala dos estagiários é a não compreensão da escrita por fruição, prazer e/ou aprendizado, e sim uma visão pragmática sobre esse processo, como pode ser visto na fala da Adrian:

Adrian: [...] eu concordo, eu acho que esse processo de ter uma visão de fora, avaliando o texto, dando um outro olhar, melhora a qualidade do produto final e ensina a gente a escrever pras próximas oportunidades que cobrarem e exigirem uma escrita.

Os processos de escrever para esses estudantes estão associados à realização de atividades acadêmicas cobradas durante a graduação. Essa consideração se aproxima de Colello (2012):

[...] em muitas instituições, a escrita não aparece senão sob a forma de provas objetivas, questionários, exercícios, ditados e cópias. Assim, o desenvolvimento das múltiplas possibilidades do escrever fica por conta do "lucro pedagógico": competências paralelas ao projeto educativo conseguidas aleatoriamente. (COLELLO, 2012, p. 78)

Diante desses apontamentos, percebemos a necessidade de trabalhar com a escrita em diferentes momentos da formação inicial de professores, pensando em uma escrita que vai além da capacidade de desenvolver trabalhos científicos ou relatórios técnicos.

Quando os estudantes foram questionados sobre a construção do livro de relatos, todos os estagiários concordaram com a estagiária Fernanda:

Fernanda: Ah... eu achei muito legal, principalmente por ter devolvido para a escola tudo aquilo que a gente observou e realizou lá dentro, né? Eu nunca tinha imaginado isso... a gente sempre ia para a escola, né? Observava e às vezes realizava atividades e eles nunca tinham o retorno daquilo que fazíamos. Acho que o mais legal foi o retorno para a escola.

A fala da estagiária aponta para a importância do retorno das atividades e das discussões desenvolvidas dentro e fora da escola. Além disso, Adrian reforça 
que "permitiu enxergarmos boa parte daquilo que estudamos e observamos dentro e fora da escola, e agora... é... esse material não ficou perdido, juntamos tudo em um capitulo”. O estagiário ainda reforça a potencialidade do livro como produto da disciplina de estágio, que possibilita enxergar todo o processo desenvolvido.

\section{CONSIDERACÕES FINAIS A RESPEITO DA ESCRITA DE RELATOS NA DISCIPLINA DE ESTÁGIO SUPERVISIONADO EM QUIIMICA}

Neste trabalho, apresentamos uma proposta que vem sendo desenvolvida com os estudantes das disciplinas de Estágio, discutindo e propondo movimentos de leitura e escrita que se afastem da produção mecânica dos relatórios técnicos, possibilitando (re)pensar a linguagem e a escola. Dessa forma, além das discussões que foram desenvolvidas nas dependências da UFJF e das observações escolares, os estudantes produziram quatro relatos, os quais foram elaborados num processo dialógico de escrita e reescrita. Tais relatos foram compilados pelos estudantes em um capítulo de um livro de estágio, entregue aos professores orientadores e à direção das escolas nas quais o estágio foi realizado.

Em uma roda de conversas com os estudantes sobre esse processo, foi perceptível a preferência pela produção de relatos em vez do relatório técnico que geralmente é produzido nas disciplinas de estágio. Apesar da dificuldade encontrada nesse movimento de "criação", os estudantes perceberam a importância de uma escrita vinculada ao prazer e à necessidade de se perceber como autor daquilo que produz. Além disso, os estagiários apontaram como essencial esse processo de reescrever os relatos durante os dois semestres letivos, possibilitando um novo olhar para o texto e melhorando a qualidade dos relatos. Como etapa final, os estudantes avaliaram como positiva a construção do livro de relatos, possibilitando um retorno das atividades e das discussões desenvolvidas no ambiente escolar. Apesar de o livro de relatos ter sido entregue nas escolas, não sabemos qual foi o desencadeamento desse produto, uma vez que foi entregue no fim do semestre letivo. Dessa forma, deixo indicado para que pesquisas futuras compreendam o funcionamento dos livros ao chegarem às escolas.

Apostamos, neste trabalho, no incentivo à escrita na formação inicial de professores como uma porta para mudanças na educação básica. Trabalhar com processos de escrita e construção da autoria por parte de licenciandos em Química pode contribuir significativamente para com o fomento aos processos de escrita na escola básica, uma vez que essas atividades deixam de ser responsabilidade exclusiva dos professores de língua portuguesa. A partir do momento em que o professor de química passa a trabalhar com a escrita no âmbito dessa disciplina - seus limites e possibilidades -, os processos envolvidos em escrever química e sobre química, a importância de produzir textos, reescrever, deixar o outro ler - os estudantes da educação básica passam a enxergar a química como pertencente a um contexto mais amplo do empreendimento científico. 


\section{NOTA}

${ }^{1}$ Os estudantes foram consultados, e aqueles que assim o desejaram foram identificados aqui no trabalho por pseudônimos, que foram indicados no Termo de Consentimento Livre e Esclarecido (TCLP).

\section{REFERÊNCIAS}

ALMEIDA, M. J. P. M.; CASSIANI, S.; OLIVEIRA, O. B. Leitura e escrita em aulas de Ciências: luz, calor e fotossíntese nas mediações escolares. Florianópolis: Letras contemporâneas, 2008.

BACCON, A. L. P.; ARRUDA, S. M. Os saberes docentes na formação inicial do professor de física: elaborando sentidos para o Estágio Supervisionado. Ciência \& Educação, Bauru, v. 16, n. 3, p. 507-524, 2010.

CASSIANI, S.; ALMEIDA, M. J. P. M. Escrita no ensino de Ciências: autores do ensino fundamental. Ciência \& Educação, Bauru, v. 11, n. 3, p. 367-382, 2005.

CASSIANI, S.; NASCIMENTO, T. G. Um diálogo com as Histórias de Leituras de futuros professores de Ciências. Pro-Posições, Campinas, v. 17, p. 105-136, 2006.

COLELLO, S. M. A escola que (não) ensina a escrever. 2. ed. São Paulo: Summus, 2012.

FLÔR, C. C.; CABRAL, W. A. Estranhamento: o trabalho com leituras de textos diferenciados na disciplina de Estágio Supervisionado em Química na UFJF. In: CALDERANO, M. A. (Org.). Estágio curricular: concepções, reflexões teórico-práticas e proposições. Juiz de Fora: UFJF, 2012, v. 1, p. 103-123.

FRANCISCO JUNIOR, W. E. Analisando uma estratégia de leitura baseada na elaboração de perguntas e de perguntas com respostas. Investigações em Ensino de Ciências, Porto Alegre, v. 16, n. 1, p. 161-175, 2011.

GERALDI, J. W. Linguagem e ensino: exercícios de militância e divulgação. Campinas: Mercado de Letras, 1996. $142 \mathrm{p}$.

GONÇALVES, F. P. et al. O diário de aula coletivo no Estágio da licenciatura em Química: dilemas e seus enfrentamentos. Química Nova na Escola, São Paulo, n. 30, p. 42-48, 2008.

GONÇALVES, F. P.; FERNANDES, C. S. Narrativas acerca da prática de ensino de Química: um diálogo na formação inicial de professores. Química Nova na Escola, São Paulo, v. 32, n. 2, p. 120-127, 2010.

KASSEBOEHMER, A. C.; FERREIRA, L. H. O espaço da prática de ensino e do Estágio Curricular nos cursos de formação de professores de Química da IES públicas paulistas. Química Nova, São Paulo, v. 31, n. 3, p. 694-699, 2008.

MINER, Horace. Ritos corporais entre os Nacirema. In: ROONEY, A. K.; DE VORE P. L. (Org.). You and the others: Readings in Introductory Anthropology. Cambridge: Erlich, 1976.

ORLANDI, E. P. Análise de Discurso: princípios e procedimentos. 10. ed. Campinas: Pontes Editores, 2012.

PIMENTA, S. G. O Estágio na Formação de Professores: unidade Teoria e Prática? 11. ed. São Paulo: Cortez, 2012.

PIMENTA, S. G.; LIMA, M. S. L. Estágio e Docência. São Paulo: Cortez, 2012. v. 1.

QUEIROZ, S. L. A linguagem escrita nos cursos de graduação em Química. Química Nova, São Paulo, v. 24, n. 1, p. 143-146, 2001. 
SILVA, R. M. G.; SCHNETZLER, R, P. Concepções e ações de formadores de professores de Química sobre o Estágio Supervisionado: propostas brasileiras e portuguesas. Química Nova, São Paulo, v. 31, n. 8, p. 2174-2183, 2008.

SILVA, W. R. O que revelam os relatórios de Estágio Supervisionado sobre o letramento do professor em formação inicial? In: ENCONTRO NACIONAL DE DIDÁTICA E PRÁTICAS DE ENSINO, XVI, 2012, Campinas. Anais eletrônicos... Campinas: Unicamp, 2012, p. 2-13.

Recebido: 05/10/2015

Aprovado: $14 / 11 / 2016$

\section{Contato:}

Wallace Alves Cabral

Rua José Renato Borges de Almeida, 99 Cond. via do Sol - Bairro Santos Dumont Juiz de Fora - MG - 36.038-015 